\title{
LA CRISIS DEL DETECTIVE \\ EN LOS HOMBRES MOJADOS \\ NO TEMEN A LA LLUVIA \\ DE JUAN MADRID
}

Carlos Cuadra

Stephen F. Austin State University

https://doi.org/10.18778/8220-195-6.21

\section{Resumen}

La novela negra española durante el tiempo de la transición democrática tuvo un carácter político y sirvió para desarrollar una crítica de la sociedad. Juan Madrid, uno de los representantes del género estableció un modelo narrativo con las novelas protagonizadas por el detective Toni Romano que se convirtió, de alguna manera en el representante de los ideales de la izquierda. En la novela de 2016 Los Hombres mojados no temen a la lluvia, Juan Madrid desarrolla una variación de este modelo tradicional y renuncia a una visión política en aras de una visión mucho más marginal y violenta.

Palabras clave: Novela negra, Transición Democrática en España, violencia de género, Juan Madrid.

Tal vez la capacidad de crear valores que tiene la novela negra sea la razón por la que este género floreció en España durante los años de la transición democrática, tras la muerte del general Franco, un tiempo en que la sociedad española necesitaba renovar perspectivas. El universo que describen las novelas negras de Manuel Vázquez Montalbán, Andreu Martín o Francisco González Ledesma, es sobre todo un universo político. Como quiere Antonio Calmeiro, autor de una historia del género policial en España, 
La novela policiaca en España en la última parte del siglo XX (se ha transformado en) un género político, utilizado a menudo como instrumento de observación social y crítica cultural, así como un espacio de resistencia política y subversión ideológica del statu quo por parte de muchos escritores españoles, durante y después del régimen de Franco. (Colmeiro, 2014: 15)

Cabe preguntarse en qué consisten exactamente esta crítica y esta observación, qué valores propugnan. Un caso interesante es el de Juan Madrid (Málaga, 1947), el autor en el que se centran estas páginas. Juan Madrid es un autor mítico y al mismo tiempo alternativo. Excluido habitualmente por los críticos y antólogos, es reconocido por muchos aficionados al género como "uno de los fundadores de la novela negra española” (Galindo, 2017). Juan Madrid no escribe textos políticamente correctos. Después de más de treinta años de oficio novelístico, mantiene una posición de resistencia al poder establecido y se reafirma en una interpretación política del género negro, y dice querer llevarla hasta sus últimas consecuencias. En sus propias palabras:

La buena novela negra está dando una visión de la realidad, una propuesta de mirada a la realidad, y eso ha molestado muchísimo y sigue molestando en la actualidad. La literatura que merece la pena te cuenta historias que te hacen pensar que todo lo que te han contado es verdad, o podría serlo, y ha ocurrido y sucedido mientras te lo estaban contando. Debe fomentar el conocimiento de la sociedad, de sus puntos negros e inquietar y revolver a la gente. (Seoane, 2017)

Es de notar cómo el escritor comienza diciendo que la literatura negra es ficción y acaba declarándola capaz de un conocimiento objetivo de la sociedad. Parece que él mismo cree que su ficción es más real que la realidad misma. Juan Madrid ofrece una visión personal y parcial de la realidad. Quiere hacerse portavoz del sector más oprimido de la sociedad española de la sociedad democrática. Sus novelas ofrecen una visión alternativa, capaz de desenmascarar una serie de usos corrompidos y de proponer 
otros nuevos: democracia, libertad, igualdad. Sin embargo, pese a un declarado compromiso en contra de la dictadura de Franco (Galindo, 2017) los valores del franquismo, latentes en la sociedad española de la transición democrática, transpiran en la primera novela de Juan Madrid, Un beso de amigo, escrita, en 1980, esto es, incluso antes del 23-F, del afianzamiento del sistema democrático en España y de la llegada del PSOE al poder.

Un beso de amigo, narrada en primera persona, se basa sobre todo en el modelo establecido por Raymond Chandler. Toma de las novelas de Chandler situaciones y personajes que Juan Madrid adapta, de manera muy personal, a los bajos fondos de la capital de España. La novela hace alarde de una considerable agilidad narrativa y muestra el excelente oído que su autor tiene para el diálogo. Sin embargo, no hay en ella criminales memorables. Tal vez la razón de esta carencia esté en el mismo mundo que Juan Madrid quiere describir. El régimen franquista de los años setenta no se distinguió por el talento ni la genialidad de sus líderes, que crearon una sociedad mediocre y anquilosada, la continuación de la "España de charanga y pandereta" de Antonio Machado. El pretexto para desarrollar la trama son unos documentos comprometedores que muestran los vínculos secretos de un rico empresario llamado Elósegui con una serie de grupos de agitadores fascistas. Esa es la excusa que nos permite conocer y apreciar las virtudes de Toni Romano, el detective protagonista. Toni es un hombre del pueblo: exboxeador, expolicía y enemigo a ultranza del franquismo. Uno de los personajes secundarios de la novela define a Toni como "El guerrerro del antifaz. Un muerto de hambre que se cree el Guerrero del Antifaz" (Madrid, 1980: 158)

El guerrero del antifaz, el más célebre héroe del cómic de la posguerra española, representaba, paradójicamente, la quintaesencia de los valores del franquismo. Toni, es progresista y democrático, pero tiene una idea maniquea del bien y del mal. Además, Toni es muy violento, mucho más violento que Phillip Marlowe, aunque su agresividad parece justificarse como una forma de impartir justicia. Toni no comete errores. Con preternatural discernimiento, sólo castiga a los malos, a los que se lo merecen. Un ejemplo es el de Romero, el guardia de seguridad de 
un aparcamiento donde Yumbo, un amigo de Toni, es asesinado. Romero le dice a Toni que Yumbo era un vago. Toni responde:

- ¡Qué simpático eres, Romero!

- Más de una vez estuve a punto de echar a ese vago. Pero me daba pena. Yo no soy así.

- Romero, ¿Qué hora es? -le pregunté

- Las nueve, ¿por qué?

- Para que te acuerdes -le respondí y le lancé la derecha a la boca. Abrió los brazos y tropezó contra la cristalera. No tuve siquiera que sacudirle otro. (Madrid, 1980: 139)

Gracias a ese derroche de agresión física y chulería, Toni Romano tiene efectivamente mucho de Cruzado, en el sentido medieval del término. Sus opiniones se parecen a veces a ordalías. Estas prácticas incluyen también la violencia de género. Este es el consejo de Toni a un marido engañado: "Háblale. Esta noche le hablas y se acabó. O mejor le sacudes un poco con un cinturón no muy fuerte y luego os vais de vacaciones. Dora trabaja mucho." (Madrid, 1980: 120)

Es necesario pegar a la esposa infiel, pero no sin bondadosa comprensión. Hay que hacerlo por el bien de ella, sin inquina, poniéndose en su lugar.

La capacidad de discernir entre el bien y el mal de Toni parece ser una consecuencia de su fuerza física. Toni tiene razón porque es el más fuerte. Su atractivo es también consecuencia de preeminencia darwinista sobre otros miembros de la especie. Este atractivo se trasluce en una relación especial con las mujeres que le rodean, muchas de ellas prostitutas. Las mujeres son el público de Toni. Se rinden antes o después ante su carisma. Lo encuentran cautivador y se le insinúan de manera abierta. Toni triunfa sobre todo como macho de la especie. Una empleada de un bar americano con la que disfruta una noche de pasión le dice:

Tienes una cara muy rara, me fijé en cuanto te vi. De mongol, o algo así, pero eres guapo. No guapo, guapo pero guapo. Y tienes unos brazos demasiado grandes para la chaqueta. 
- Y añade, romántica: ¿Estoy diciendo tonterías? (Madrid, 1980: 144)

Toni, por supuesto, no corresponde a sus admiradoras. Como el detective ideal de Chandler, no se deja mancillar. Es puro, es superior. No se implica sentimentalmente.

Como contrapunto de esta loa constante a la masculinidad tradicional aparece en la novela el fantasma de la castración. En el primer capítulo, una adolescente a la que Toni ha venido a rescatar de unos matones no tiene tiempo de caer en las redes del detective. Antes de que Toni pueda desplegar sus encantos, la chica le increpa a uno de sus captores diciendo “ ¡Córtale la polla, Luis! ¡Anda, córtasela!" (Madrid, 1980: 13)

Como cabría esperar, Toni le noquea de inmediato al tal Luis de un directo en la mandíbula y la amenaza no se materializa. Pero el tema de la castración reaparece en las últimas páginas de la novela cuando Marga, la esposa de Elósegui, le revienta los genitales de un tiro a uno de los esbirros a los que ha seducido, con sus artes de mujer, para liberar a Toni. Marga sumisa y complaciente cuando se trata del detective, es una mantis religiosa con los demás personajes masculinos.

Toni es el único que sabe "tratar a las mujeres". Para los demás representantes del género masculino, ellas son un colectivo incomprensible, peligroso, letal. Por supuesto, el comportamiento irresistible de Toni no se basa en ninguna estrategia. Es el instinto, la naturaleza, lo que le da a Toni su preeminencia. En suma, en una novela en el que no existe un criminal brillante ni poderoso, el detective muestra una moralidad más ambigua que nunca.

Es posible que la explicación de todas estas particularidades se encuentre en una entrevista que Juan Madrid al diario Sur en la que afirma: "Cada novela es una venganza. De alguien que se rio de ti, que te insultó, te negó o te ninguneó; de la chica que te dejó en una esquina y se negó a bailar contigo" (Lorenci, 2017). Desde ese punto, Un beso de amigo de Juan Madrid es una excursión por el imaginario de su autor. En ella, Toni Romano salda las cuentas de Juan Madrid. Más que un diagnóstico objetivo de la España del final de los años setenta, consiste, pudiéramos decir, en el negativo 
fotográfico de una serie de carencias, que, al ser compensadas en la novela, nos permiten hacernos una imagen del funcionamiento de aquella sociedad: violencia reprimida, miedo a la sexualidad, confusión moral, aislamiento, incomunicación, etc.

Podemos concluir que Un beso de amigo es un texto que ofrece un diagnóstico crítico de la sociedad española de su tiempo, pero no escapa a muchos de los usos y presupuestos ancestrales que la inmovilizan. Pese a todo, la novela comunica un tono de optimismo y esperanza en el futuro.

Pero este optimismo un tanto ingenuo no se mantuvo por mucho tiempo en la obra literaria de Juan Madrid. En los años 90 y tras varias novelas, el personaje de Toni Romano pierde actualidad. Este cambio de tono corre en paralelo con el desengaño político que muestra Juan Madrid en sus declaraciones públicas. He aquí el fragmento de una entrevista de noviembre de 2017:

La Transición no destruyó el franquismo, lo cambió, lo modificó con las élites sociales y políticas que son las que gobiernan ahora, pero entonces no se reformó este país en nada. (...) El error fue muy grande, hubo un engaño y los españoles nos creímos todos a Felipe González y su pandilla, que como vemos van por otro camino. Es algo muy característico de mi generación, darse cuenta de que lo que ocurrió en este país fue un engaño absoluto. (Sedane, 2017)

Juan Madrid no renuncia a sus ideales y tampoco usa el ejemplo de estos políticos corruptos para construir personajes interesantes, criminales con dimensión y profundidad. Se limita a ampliar su definición de Franquismo. En los años 90, la izquierda ha pasado a ser parte de los poderes establecidos. El diálogo político real ha desaparecido en España. Este desengaño radical de los políticos de la transición democrática es la primera clave en el cambio de la narrativa de Juan Madrid en el siglo XXI. La segunda, es un intento de ponerse a la altura de los tiempos en lo referente a la política de género. Juan Madrid pasa a describir un mundo en que todos los partidos políticos mayoritarios son corruptos, pero en el que no todas las mujeres son prostitutas. Para comprender 
los términos de este cambio tal vez sea útil acercarse a una de las últimas novelas del autor, la titulada Los hombres mojados no temen a la lluvia.

La fórmula en esta novela es más o menos la misma que la de Un beso de amigo. El centro de la trama en este caso es un filme porno sadomasoquista y comprometedor. El malvado plutócrata se llama ahora Barrera, no Elósegui. En el transcurso de la investigación para recuperar el filme porno se descubren las actividades ilegales de una trama de millonarios facinerosos. La gran diferencia entre Un beso de amigo y Los hombres mojados no temen a la lluvia es que en esta última Toni Romano está ausente. El papel de protagonista lo retoman dos nuevos personajes, que, como las condensaciones de los sueños, forman versiones complementarias del héroe masculino. Uno de ellos representa el aspecto presentable de Toni Romano; el otro, su sombra. El protagonista digamos, políticamente correcto, la luz, se llama Liberto Ruano, quien narra la novela en primera persona. Liberto es un abogado culto, pacífico y defensor de los oprimidos que se ve envuelto en la búsqueda del filme porno en cuestión. Representa los valores de la civilización y la legalidad. Sin embargo, pese a todas sus cualidades, no posee los atributos sobrenaturales de Toni Romano. Su bufete pasa por apuros económicos y dista mucho de ser irresistible para las mujeres. Precisamente su vida amorosa, su debilidad, es la que le lleva a la ruina.

Liberto es el amante de Julia, la esposa de Barrera, el "malo" de la novela, y está muy enamorado de ella. Como su propio nombre nos revela, Liberto es un gourmet del amor, un intelectual del sexo. Un libertino. Su técnica de seducción consiste en largas peroratas sobre literatura y zoología erótica. He aquí uno de sus monólogos con Julia:

Existe una antigua leyenda mediterránea. La de un pez hembra que devora a su macho. Pero resulta que es verdad. Su nombre científico es Xarroco Abisal y en el lenguaje popular 'pez plata'. Ese pez, que puede llegar a pesar hasta tres kilos y habita en las profundidades abisales del mar, tiene una particularidad. La hembra de su especie atrae al macho en la época del 
apareamiento y ya no se separa de él. Se alimenta de su carne mientras copulan hasta que es consumido por completo por la hembra. Cuando eso ocurre, la hembra busca otro macho nuevo (Madrid, 2013: pos. 416).

Podríamos decir que Liberto intenta conquistar a su objeto erótico, no mediante un derroche de violencia, como Toni Romano, sino por medio de la palabra, imponiendo una superioridad intelectual. Por desgracia, Julia, pese a sus continuas declaraciones de amor hacia el abogado, se cansa de él y decide quitárselo de encima contratando a dos matones para que lo castren. La ablación se lleva a cabo sólo a medias y, tras una oportuna intervención quirúrgica, Liberto logra conservar su pene, pero sus peores miedos se han hecho realidad. Ha caído en las redes de una mantis religiosa, o si se prefiere, de la hembra del Xarroco Abisal, y se ha convertido en un eunuco psicológico. La novela ha llegado a un callejón sin salida.

Aquí entra en escena el segundo personaje protagonista, la mitad oscura de Toni Romano, un deus ex machina llamado Aurelio Pescador. Aurelio representa la masculinidad salvaje y marginal. Es un viejo de setenta y cuatro años que trabaja de forma intermitente en el bufete de Liberto como "guardaespaldas o informante". Cuando Liberto se convierte en un hombre sin atributos, Aurelio toma el relevo. Aurelio Pescador comparte muchas de las características de Toni Romano pero es, al fin y a la postre un sicario. Representa lo peor de ambos mundos, el del detective y el del criminal. Resulta que en realidad es un asesino profesional de la mafia calabresa. No es un criminal vulgar, sino que desciende de la aristocracia de Aragón, con el elaborado código de honor (como el quería Raymond Chandler para su detective) de la Cosa Nostra, un código de sórdidos asesinatos y negocios con drogas. Cobrándose unas cuantas vidas de forma fría y despiadada, Aurelio restablece el orden y pone fuera de peligro a ...su hijo Liberto. Porque, en una anagnórisis postrera, descubrimos esta rocambolesca relación paterno filial entre ambos personajes que nos hace verlos como dos caras de la misma moneda. 
¿Cómo interpretar este nuevo giro en la producción del novelista malagueño? Juan Madrid nos ofrece una vez más una narración vívida, escrita en prosa precisa y desarrollada con gran riqueza imaginativa. Técnicamente se encuentra en plena forma, como corresponde a alguien que aún hoy se declara con orgullo como un practicante de la novela negra en España:

Hay feministas que dicen 'sin mujeres aquí no se hace nada', pero están equivocadas, eso no significa que haya una transformación en la novela negra. Pero ya te digo, es que a mí no me gusta lo que se hace ahora en general porque lo que se hace es novela policíaca, no negra, y a mí no me gusta la novela policíaca. (Corroto, 2017)

Tal vez la diferencia entre la novela policiaca y la novela negra se encuentre en el motivo de la venganza. El detective de la novela policiaca resuelve el enigma; el de la novela negra va más allá. Juzga y se venga, como nos decía Juan Madrid en la cita reproducida anteriormente. La venganza que ejercía Toni Romano en las primeras novelas de Madrid no consistía en el asesinato. Después de todo, Toni representaba a las fuerzas progresistas de una sociedad con la esperanza de alcanzar un futuro justo de forma legal. Aurelio Pescador es distinto. Es un miembro de la mafia calabresa y es un personaje impostado. No representa a ningún estrato de la sociedad. Pertenece a otro mundo, a otra novela. No tiene verosimilitud en la España de los años dos mil. Agotado el modelo de Toni Romano, agotados sus principios e ideales, desenmascaradas las fuerzas políticas de la izquierda que el detective representaba, Juan Madrid no desarrolla un nuevo discurso de resistencia política y subversión ideológica. No hay una solución crítica a la corrupción y el marasmo de la sociedad española. La única forma de restablecer el equilibrio es mediante el crimen. Los hombres mojados no temen a la lluvia es una novela que se debate entre la impotencia de Liberto Ruano y la marginalidad criminal de Aurelio Pescador. El guerrero del antifaz se ha convertido en un asesino, tal vez, no vulgar, 
pero sí despiadado y, desde luego, inverosímil. Toni Romano nos daba una visión del mundo en el que todavía era posible esperar justicia. Aurelio Pescador perpetúa una situación criminal sin hacer una propuesta ideológica. La venganza ya no es un medio de restaurar el orden sino que se ha convertido en un recurso desesperado, la única garantía de la supervivencia de la clase trabajadora en España.

\section{Bibliografía}

Chandler, R. (1988). The simple Art of Murder. New York: Vintage Books.

Colmeiro, J. (1994). La novela policiaca española. Barcelona: Anthropos Editorial.

Colmeiro, J. (2014). "Novela policiaca, novela política”, [en línea] $<$ https://dialnet.unirioja.es/descarga/articulo/5247874.pdf > [20.04.2018].

Corroto, P. (2017). “Juan Madrid: «El PSOE nos engañó: nunca ha sido de izquierdas, ni siquiera en los 80 '»" [en línea], <https:// www.elconfidencial.com/cultural/2017-07-11/juan-madrid-semana-negra-gijon_1412790/> [25.04.2018].

Galindo, J.C. (2017). "Cuatro libros de un autor clásico de la novela negra española”, [en línea] <https//elpais.com/cultura/2017/09/28/elemental/1506616954_689758.html> [22.04.2018].

Galindo, J.C. (2017). "Juan Madrid evoca en su nueva novela la memoria de la lucha antifranquista" [en línea] $<$ https://www. malagahoy.es/ocio/Juan-Madrid-novela-memoria-antifranquista_0_1134486701.html> [20.04.2018].

Lorenci, M. (2017). "Memoria y desmemoria de Juan Madrid" [en línea] https://www.diariosur.es/culturas/libros/201705/10/ memoria-desmemoria-juan-madrid-20170510003938-v.html [17.05.2017]

Madrid, J. (1980). Un beso de amigo. Madrid: Sedmay

Madrid, J. (2013). Los hombres mojados no temen a la lluvia. Madrid: Alianza editorial. Documento Kindle. 
Poe, E.A. "The Murders of the Rue Morgue", [en línea] <https:// americanenglish.state.gov/files/ae/resource_files/the_murders_in_the_rue_morgue.pdf $>$ [20.04.2019].

Sedane, A. (2017). "Juan Madrid: «La buena novela negra debe molestar a alguien»", [en línea] <https://elcultural.com/noticias/letras/Juan-Madrid-La-buena-novela-negra-debe-molestar-a-alguien/10079> [20.04.2018]. 